\title{
Experimental design approach to the optimization of PAHs bioremediation from artificially contaminated soil: application of variables screening development
}

\author{
Masoumeh Ravanipour ${ }^{1}$, Roshanak Rezaei Kalantary², Anoushiravan Mohseni-Bandpi ${ }^{3{ }^{*}}$, Ali Esrafili², \\ Mahdi Farzadkia ${ }^{2}$ and Samireh Hashemi-Najafabadi ${ }^{4}$
}

\begin{abstract}
Background: The effectiveness of bioremediation systems for PAH-contaminated soil may be constrained by physicochemical properties of contaminants and environmental factors. Information on what is the most effective factor in bioremediation process is essential in the decision of what stimulations can be taken to assist the biodegradation efficacy.

Methods: In this study, four factors of surfactant (Tween 80), humic acid (HA), salinity and nutrients in a $2^{4}$ full factorial design were screened in bioremediation of phenanthrene contaminated soil by using a consortium of bacteria.

Results: Between the employed levels of the factors only salinity had not significant effect. Optimal concentrations of surfactant, $\mathrm{HA}$ and nutrient were obtained by a response surface design. For phenanthrene biodegradation, a central composite face centred design (CCFD) showed that nutrient, surfactant and HA concentrations had highly significant, significant and insignificant effects, respectively. The best conditions with $87.1 \%$ phenanthrene biodegradation were $150 \mathrm{mg} \mathrm{HA} / \mathrm{Kg}$ soil, $12.68 \mu \mathrm{g} / \mathrm{L}$ surfactant, and nutrients as $\mathrm{K}_{2} \mathrm{HPO}_{4}, 0.8 ; \mathrm{KH}_{2} \mathrm{PO}_{4}, 0.2$ and $\mathrm{KNO}_{3}, 1 \mathrm{~g} / \mathrm{L}$. A high similarity was between the model prediction and experimental results.
\end{abstract}

Conclusions: This study showed that nutrient with $81.27 \%$ efficiency could be considered as the most effective factor for practical implications of bioremediation process for PAHs contaminated soil cleanup strategies.

Keywords: Bioremediation, Polycyclic Aromatic Hydrocarbons, Response Surface Method, Nutrient, Tween80

\section{Background}

Petroleum derivatives are introduced into the environment through different ways such as anthropogenic activities, incomplete combustion of petroleum products, wood and coal, undesirable discharging of oil tankers, spills around petroleum refineries and gas plant facilities [1]. Polycyclic Aromatic Hydrocarbons (PAHs) are a group of these compounds with carcinogenic and toxic potentially $[2,3]$ which contribute to environmental

\footnotetext{
* Correspondence: a.mohseni8@yahoo.com

${ }^{3}$ Department of Environmental Health Engineering, School of Public Health, Shahid Beheshti University of Medical Sciences, Tehran, Iran

Full list of author information is available at the end of the article
}

contamination and health hazards. Soil and sediments are the most important environmental reservoir for PAHs.

At present, employing biological treatment is the most popular and cost - effective strategy among the different methods to remove these pollutants from the soil [4]. However, successful application of bioremediation is often limited by environmental, physical and chemical factors [5] such as availability of pollutants to undergo biological transformations [6] toxicity and complex structures of PAHs derivatives, limitation for nitrogen, phosphorus or other nutrients, $\mathrm{pH}$ and temperature [7].

One of the main factors limiting bioavailability is the low aqueous solubility of PAHs. Addition of surfactant 
can be used for increasing the phase partitioning of organic compounds and their bioavailability. On the other hand bioavailability may be decreased by up taking of contaminants into the surfactant micelle [8]. Thus, the concentration of surfactant plays an important role in biodegradation of PAHs.

Many studies have been conducted to overcome problems related to the poor bioavailability of PAHs by using organic matter. Borresen and Rike [9] have shown that humic substances (HS) can increase the solubility of PAHs leads in increasing the bioavailability of PAHs in soil.

Nutrient such as nitrogen and phosphorus are the other important factors on biodegradation. Microorganisms need for nutrients similar to their composition of cells [10,11]. Betancur-Galvis LA et al. [12] used biosolid and inorganic fertilizer in bioremediation of phenanthrene.They found that the removal of phenanthrene in the soil with fertilization was 25 fold more than the other soils. There is a relation between mineralization rates of phenanthrene and the initial concentrations of nitrogen and phosphorus in the soils [13].

The marine soil and sediment is one of the most petroleum contaminants sites, so the salinity is an important factor which must be investigated. Minai-Tehrani D. et al. [14] showed that increasing salinity content of soil had decreasing effect on the biodegradation of total crude oil and PAHs.

The bioremediation strategy is dependent on the optimizing the factors which affect on the microbial growth and biodegradation of pollutant [15]. In combination of several factors, the effect of anyone may be influenced by the others and interactions among them may be occurred too.

The experimental design can be used for optimizing operational conditions for the multivariable system [16] and the interaction between variables would be considered too [17]. The number of experiment's runs would be reduced by statistical design of experiments $[17,18]$. In this study numerous factors, involving surfactant (Tween 80 (Su.)), salinity (Sal.), soil nutrients ( $\mathrm{N}, \mathrm{P}$ $(\mathrm{Nu}$.$) ) and organic matters (humic acid (HA)), individu-$ ally and in combination, have been studied to remedy PAH artificially contaminated soils. The aim of this study was to investigate the effect of physicochemical factors; HA, surfactant (Tween 80), salinity and nutrient $(\mathrm{N}, \mathrm{P})$ together on the bioremediation of phenanthrene a three-ring PAH, an appropriate model compound, in soil slurry. In order to find out the most effective factor and the sequence importance of them in biodegradation of phenanthrene a three-ring PAH in the soil slurry, the study was conducted in two phase: 1) Screening the factors by using full factorial experimental design, and 2) Optimization of the phenanthrene-contaminated soil biodegradation by using a central composite face centered design (CCFD) under response surface methodology (RSM). Then the optimized condition was examined in PAHs real contaminated soil.

\section{Methods \\ Chemicals}

Acetone in HPLC grade was purchased from ROMIL Company. Phenanthrene (Purity > 98\%), $\mathrm{NaCl}$ and chemical materials for mineral salt medium (MSM) were purchased from Merck Company. HA and Tween 80 were supplied by Sigma Aldridge and Fluka, respectively. The formula of $\mathrm{HA}$ was $\mathrm{C}_{17} \mathrm{H}_{17} \mathrm{BrN}_{2} \mathrm{O}_{5}$. Nutrient Broth and R2A Agar were purchased from BIOMARK Company.

\section{Phenanthrene biodegradation}

Clean soil was collected from a depth of $5-20 \mathrm{~cm}$ of ground's surface, Tehran, Iran. It was air dried and passed through a 2-mm sieve. The soil was classified as sand (consisted of $89 \%$ sand, $11.9 \%$ silt and 5\% clay) by the use of standard sieves. Total nitrogen and phosphorus were $0.025 \%$ and $0.0012 \%$, respectively. Total organic carbon was $0.18 \%$. The $\mathrm{pH}$ and electrical conductivity (EC) were 7.4 and $3.2 \mathrm{ds} / \mathrm{m}$, respectively.

Two grams of dry soil was placed into $50 \mathrm{~mL}$ Erlenmeyer flask as non-continuous bioreactors. The bioreactors containing clean soil were autoclaved. Then, it was spiked with dissolved phenanthrene in acetone to have $500 \mathrm{mg}$ phenanthrene/kg dry soil. The bioreactors containing spiked soil were placed in a shaker (Heidolph, ProMax 2020 model) at the velocity of $180 \mathrm{rpm}$ in room temperature and dark condition to have a uniform dispersion of phenanthrene and evaporation of acetone.

The soil was inoculated with a consortium of bacteria in different concentration of MSM with an optical density of 1 at $630 \mathrm{~nm}$ [5] using CECIL UV/Vis spectrophotometer (model 7100). The bacterial consortium was consisted of Bacillus sporogenes, Bacillus licheniformis, Capnocytophaga ochracea (presumably), Acinetobacter sporogenes and Staphylococcus xylosus. Enrichment of the consortium and the potential of it in bioremediation of phenanthrene contaminated soils had been proved in our previous study [6]. The base of MSM was contained of the following (per liter): $0.2 \mathrm{~g} \mathrm{MgSO}_{4} .7 \mathrm{H}_{2} \mathrm{O}, 0.1 \mathrm{~g}$ $\mathrm{CaCl}_{2} \cdot 2 \mathrm{H}_{2} \mathrm{O}, 0.1 \mathrm{~g} \mathrm{NaCl}, 0.01 \mathrm{~g} \mathrm{FeCl}_{3} \cdot 6 \mathrm{H}_{2} \mathrm{O}$ and $1 \mathrm{~mL}$ trace element solution. The trace element solution contained the following (per liter): $23 \mathrm{mg} \mathrm{MnCl}_{2} \cdot 2 \mathrm{H}_{2} \mathrm{O}$, $30 \mathrm{mg} \mathrm{MnCl}$, $32 \mathrm{mg} \mathrm{H} \mathrm{H}_{3} \mathrm{BO}_{3}, 39 \mathrm{mg} \mathrm{CoCl} 2.2 \mathrm{H}_{2} \mathrm{O}, 50 \mathrm{mg}$ $\mathrm{ZnCl}_{2}, 30 \mathrm{mg} \mathrm{NaMnO}{ }_{4} \cdot 2 \mathrm{H}_{2} \mathrm{O}$ and $20 \mathrm{mg} \mathrm{NiCl}$ [5]. Then the amount of $\mathrm{K}_{2} \mathrm{HPO}_{4}, \mathrm{KH}_{2} \mathrm{PO}_{4}, \mathrm{KNO}_{3}$, HA, Surfactant and $\mathrm{NaCl}$ were added according to Tables 1 and 2 for phase 1 and 2 respectively. The $\mathrm{pH}$ was adjusted to $6.8 \pm 0.2$ using a pH meter ( $\mathrm{HACH} 40 \mathrm{~d}$ model). At the end, the slurry of soil liquid ratio was $10 \% \mathrm{w}$ : $\mathrm{v}$ [6]. All the samples and their similar blanks were put in the 
Table 1 Actual values coded and of variables used in the full factorial $\left(2^{4}\right)$ design

\begin{tabular}{|c|c|c|c|c|c|c|}
\hline \multirow[t]{3}{*}{ Run } & \multicolumn{6}{|c|}{ Actual value/coded Levels } \\
\hline & \multirow{2}{*}{$\begin{array}{l}\text { Salinity (Sal.) } \\
\% W / V\end{array}$} & \multirow{2}{*}{$\begin{array}{l}\text { Surfactant } \\
\text { (Su.)L/L } \mu\end{array}$} & \multirow{2}{*}{$\begin{array}{l}\text { Humic Acid } \\
\text { (HA)mg/Kg }\end{array}$} & \multicolumn{3}{|c|}{ Nutrient $(\mathrm{N}, \mathrm{P})(\mathrm{Nu}.) \mathrm{g} / \mathrm{L}$} \\
\hline & & & & $\mathrm{KNO}_{3} \mathrm{KH}_{2} \mathrm{PO}_{4}$ & & \\
\hline R1 & $0(-1)$ & $0(-1)$ & $0(-1)$ & $0.000132(-1)$ & $0.000103(-1)$ & $0.0017(-1)$ \\
\hline R2 & $200(1)$ & $0(-1)$ & $0(-1)$ & $0.000132(-1)$ & $0.000103(-1)$ & $0.0017(-1)$ \\
\hline R3 & $0(-1)$ & $13(1)$ & $0(-1)$ & $0.000132(-1)$ & $0.000103(-1)$ & $0.0017(-1)$ \\
\hline R4 & $200(1)$ & $13(1)$ & $0(-1)$ & $0.000132(-1)$ & $0.000103(-1)$ & $0.0017(-1)$ \\
\hline R5 & $0(-1)$ & $0(-1)$ & $2(1)$ & $0.000132(-1)$ & $0.000103(-1)$ & $0.0017(-1)$ \\
\hline R6 & $200(1)$ & $0(-1)$ & $2(1)$ & $0.000132(-1)$ & $0.000103(-1)$ & $0.0017(-1)$ \\
\hline R7 & $0(-1)$ & $13(1)$ & $2(1)$ & $0.000132(-1)$ & $0.000103(-1)$ & $0.0017(-1)$ \\
\hline R8 & $200(1)$ & $13(1)$ & $2(1)$ & $0.000132(-1)$ & $0.000103(-1)$ & $0.0017(-1)$ \\
\hline R9 & $0(-1)$ & $0(-1)$ & $0(-1)$ & $0.8(1)$ & $0.2(1)$ & $1(1)$ \\
\hline R10 & $200(1)$ & $0(-1)$ & $0(-1)$ & $0.8(1)$ & $0.2(1)$ & $1(1)$ \\
\hline R11 & $0(-1)$ & $13(1)$ & $0(-1)$ & $0.8(1)$ & $0.2(1)$ & $1(1)$ \\
\hline $\mathrm{R} 12$ & $200(1)$ & $13(1)$ & $0(-1)$ & $0.8(1)$ & $0.2(1)$ & $1(1)$ \\
\hline R13 & $0(-1)$ & $0(-1)$ & $2(1)$ & $0.8(1)$ & $0.2(1)$ & $1(1)$ \\
\hline R14 & $200(1)$ & $0(-1)$ & $2(1)$ & $0.8(1)$ & $0.2(1)$ & $1(1)$ \\
\hline R15 & $0(-1)$ & $13(1)$ & $2(1)$ & $0.8(1)$ & $0.2(1)$ & $1(1)$ \\
\hline R16 & $200(1)$ & $13(1)$ & $2(1)$ & $0.8(1)$ & $0.2(1)$ & $1(1)$ \\
\hline
\end{tabular}

Table 2 Experimental matrix for central composite design for optimization

\begin{tabular}{|c|c|c|c|c|c|c|c|}
\hline \multirow[t]{3}{*}{ Run } & \multicolumn{5}{|c|}{ Actual value/coded levels } & \multicolumn{2}{|c|}{ Removed amount of phenanthrene $(\mathrm{mg} / \mathrm{Kg})$} \\
\hline & \multirow[t]{2}{*}{$\mathrm{HA}(\mathrm{mg} / \mathrm{Kg})$} & \multirow[t]{2}{*}{ Su. $(\mu \mathrm{g} / \mathrm{L})$} & \multicolumn{3}{|c|}{ Nu. $(N, P)(g / L)$} & \multirow[b]{2}{*}{ Experimented value } & \multirow[b]{2}{*}{ Predicted value } \\
\hline & & & K2HPO4 & $\mathrm{KH} 2 \mathrm{PO} 4$ & KNO3 & & \\
\hline R1 & $0(-1)^{*}$ & $5(-1)$ & $0.4(-1)$ & $0.1(-1)$ & $0.5(-1)$ & 196.4 & 190.67 \\
\hline R2 & $150(+1)^{*}$ & $5(-1)$ & $0.4(-1)$ & $0.1(-1)$ & $0.5(-1)$ & 222 & 213.63 \\
\hline R3 & $0(-1)$ & $13(+1)$ & $0.4(-1)$ & $0.1(-1)$ & $0.5(-1)$ & 208.4 & 214.23 \\
\hline R4 & $150(+1)$ & $13(+1)$ & $0.4(-1)$ & $0.1(-1)$ & $0.5(-1)$ & 275.7 & 274.69 \\
\hline R5 & $0(-1)$ & $5(-1)$ & $0.8(+1)$ & $0.2(+1)$ & $1(+1)$ & 332.1 & 331.61 \\
\hline R6 & $150(+1)$ & $5(-1)$ & $0.8(+1)$ & $0.2(+1)$ & $1(+1)$ & 342.8 & 335.47 \\
\hline R7 & $0(-1)$ & $13(+1)$ & $0.8(+1)$ & $0.2(+1)$ & $1(+1)$ & 380.8 & 387.67 \\
\hline R8 & $150(+1)$ & $13(+1)$ & $0.8(+1)$ & $0.2(+1)$ & $1(+1)$ & 424.8 & 429.03 \\
\hline R9 & $0(-1)$ & $9(0)$ & $0.6(0)$ & $0.15(0)$ & $0.75(0)$ & 247.6 & 281.05 \\
\hline $\mathrm{R} 10$ & $150(+1)$ & $9(0)$ & $0.6(0)$ & $0.15(0)$ & $0.75(0)$ & 260.8 & 313.21 \\
\hline R11 & $75(0)^{*}$ & $5(-1)$ & $0.6(0)$ & $0.15(0)$ & $0.75(0)$ & 283.6 & 267.85 \\
\hline $\mathrm{R} 12$ & $75(0)$ & $13(+1)$ & $0.6(0)$ & $0.15(0)$ & $0.75(0)$ & 380 & 326.41 \\
\hline R13 & $75(0)$ & $9(0)$ & $0.4(-1)$ & $0.1(-1)$ & $0.5(-1)$ & 234.2 & 223.31 \\
\hline R14 & $75(0)$ & $9(0)$ & $0.8(+1)$ & $0.2(+1)$ & $1(+1)$ & 394.41 & 370.95 \\
\hline R15 & $75(0)$ & $9(0)$ & $0.6(0)$ & $0.15(0)$ & $0.75(0)$ & 340 & 297.13 \\
\hline $\mathrm{R} 16$ & $75(0)$ & $9(0)$ & $0.6(0)$ & $0.15(0)$ & $0.75(0)$ & 279 & 297.13 \\
\hline R17 & $75(0)$ & $9(0)$ & $0.6(0)$ & $0.15(0)$ & $0.75(0)$ & 285.2 & 297.13 \\
\hline $\mathrm{R} 18$ & $75(0)$ & $9(0)$ & $0.6(0)$ & $0.15(0)$ & $0.75(0)$ & 260.5 & 297.13 \\
\hline
\end{tabular}

*Low Level: (-1); Middle: (0); High Level: (-1). 
shaker at the velocity of $180 \mathrm{rpm}$ in room temperature $\left(22 \pm 3^{\circ} \mathrm{C}\right)$ for 8 weeks.

\section{Experimental designs}

The experiment was accomplished in two phases; screening of important variables and the levels of them that significantly influenced phenanthrene degradation, followed by optimization of variables levels by using response surface methodology.

\section{Screening of variables}

Screening step was used for identifying the important of four factors based on full factorial design $\left(2^{4}\right)$. These relevant factors were Tween 80 , as a non-ionic surfactant $(\mathrm{Su}), \mathrm{HA}$, Nutrient and Salinity in two levels of high $(+1)$ and low $(-1)$. The importance of the factors was on the base of the largest effect on the biodegradation of phenanthrene in contaminated soil. In this phase 16-run was applied to evaluate factors (variables). Table 1 illustrates the variables and their corresponding levels. The levels of the factors were on the base of previous studies in literature for PAHs bioremediation [14,19-21].

All the experiment runs were performed in triplicates and the average of them was taken as the result. Each of experiment run had the similar chemical control without any inoculation. The statistical software Design Expert V.7, (Stat-Ease, USA) was used to evaluate the analysis of variance $(\mathrm{P}<0.05)$ to determine the significance of each term.

\section{Optimization of variables by RSM}

The eventual objective of RSM is optimization of the variables by considering the interactive effects of independent factors. With the aim of increasing phenanthrene biodegradation, a central composite face centered design (CCFD) was applied with three factors, which were screened in the first phase. These factors were surfactant, HA and nutrient in 3 levels: High $(+1)$, middle (0) and low $(-1)$ with 4 center points with a CCFD under response surface methodology (RSM) (Table 2). In the first phase salinity had not significant effect on the results, so it was fixed on the $1 \% \mathrm{~W} / \mathrm{V}$.

After running the 18 trials, a second-order polynomial model corresponding to CCFD was fitted to correlate the relationship between the independent variables and the highest percent removal of phenanthrene as a response. The linear computer-generated model is given as [14] (Eq. 1):

$$
Y=\beta_{0}+\beta_{1} x_{1}+\beta_{2} x_{2}+\ldots+\beta_{k} x_{k}+\epsilon
$$

Where $y$ is the measured response; $\beta_{0}$ is an intercept, $\beta_{1}$ and $\beta_{2}$ are the linear effect (coefficients computed from the observed experimental values of y) regression terms; $\mathrm{x}_{1}$ and $\mathrm{x}_{2}$ is the coded level of independent variable; and $\mathrm{k}$ indicates the number of independent variables and $\epsilon$ is the error. The significance of each coefficient in the equation was determined by Student $\mathrm{t}$ test and P-values. Also, F-test indicated all of the factors and interactions considered in the experimental design that are statistically significant $(\mathrm{P}<0.05)$ at the 95 per cent confidence level.

\section{Determination of microbial population}

Most Probable Number (MPN) was used for identification of bacterial population at different time intervals. The bacterial suspension was diluted tenfold serially in a sterile ringer solution $(8.5 \mathrm{~g} \mathrm{NaCl}$ per $1 \mathrm{~L} \mathrm{DW})$ and added to the sterile Nutrient Broth in the ratio of $10 \%$ of volume in triplicates in five series. After 48 hours of incubation in $30^{\circ} \mathrm{C}$, the turbidity of positive growth was seen with direct observation. The population of bacterial consortium was estimated according to statistical table of MPN [6].

\section{Extraction and analysis}

The residual phenanthrene in the soil was extracted with acetone by ultrasonic homogenizer (Bandelin Sonoplus HD 2070) according to EPA 3550B (EPA) for two minutes [22]. The extracted sample was then centrifuged (Hettich D7200) for 15 minutes at $6000 \mathrm{rpm}$ and filtered by Whatman cellulose filter papers N.42 through 2$3 \mathrm{~cm}$ of glass wool. A portion of the filtered solution was used for analysis.

The extract was quantified by gas chromatography (GC; Chrompack CP 9001) using a flame ionization detector (FID) with an HP5 capillary column (length of $30 \mathrm{~m}$, inside diameter of $0.32 \mathrm{~mm}$ and a coated-film thickness of $0.2 \mu \mathrm{m})$. $\alpha$-Naphthol was used as an internal standard. Initial temperature of the oven was maintained at $100^{\circ} \mathrm{C}$ for one minute, and then it was increased at a rate of $10^{\circ} \mathrm{C} / \mathrm{min}$ until $250^{\circ} \mathrm{C}$. The injector and detector temperatures were set to $250^{\circ} \mathrm{C}$ and $270^{\circ} \mathrm{C}$, respectively. The concentration of phenanthrene was determined after the calibration of the method with standard phenanthrene samples.

\section{Results and discussion}

\section{Complete factorial design and bioremediation results}

This stage has attempted to investigate the effect of four independed variables on reducing the phenanthrene level by biodegradation. The phenanthrene removal efficiency in 16 tests using biodegradation compared with their similar control (without inoculation) in 8 weeks was shown in Figure 1 which is about the effectiveness of variables in comparison with each other and Bonferroni line (significant). In these 16 experiments the decrease of phenanthrene concentration in the soil was in 


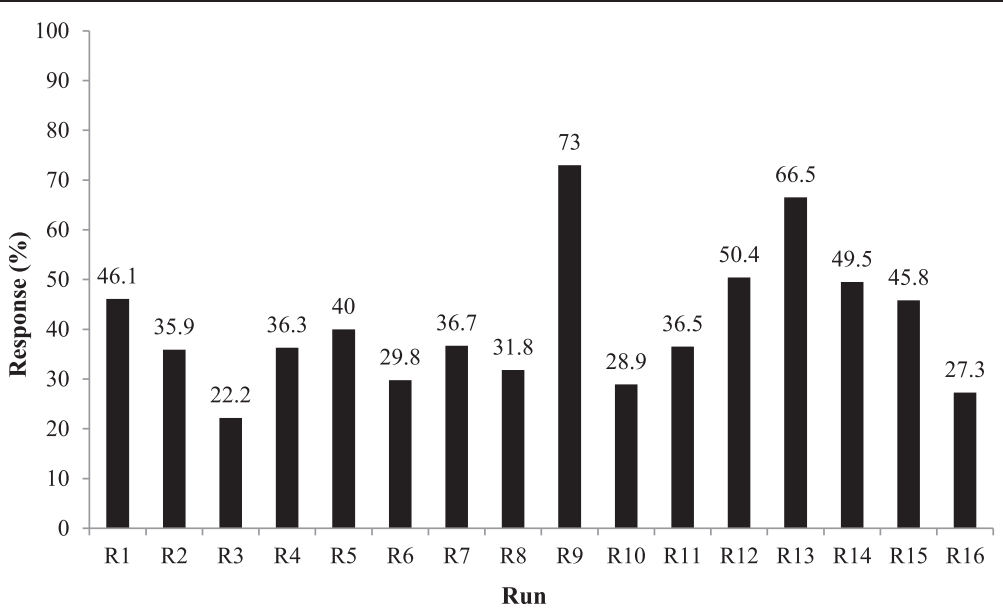

Figure 1 The phenanthrene removal percentage from Soil in 16 run of complete factorial design samples in comparison to similar controls (Response).

the range of 22-73 percent. These results indicate that the addition of microorganisms increased the rate of biodegradation. Our previous study showed that the presence of bacteria in soil has the critical role in the removal of phenanthrene [4,6]. Kästner et al. [23] reported that the biodegradation of pyrene and anthracene had been enhanced by using pure bacterial culture. This increasing was about sixfold in pyrene and tenfold in anthracene removal. The promotion of PAHs mineralization by using mix bacterial culture was reported by Jacques et al. too [24].

After performing 16 runs of complete factorial design, the statistical analysis of the responses was done with regard to the coded design matrix. The responses showed that linear term of HA, Surfactant and Nutrient have remarkable effects on phenanthrene removal efficiency, but salinity was not significant variable in these concentrations. The idea of less effect of salinity is not agree with Chen et al. [7] who reported that salinity was the most significant factor on phenanthrene biodegradation.

Analysis of variance (ANOVA) indicated that nutrient with the largest effect was the most significant variable $(\mathrm{p}<0.0001)$, and HA and Su were possibly significant. The statistically relevant effects were sorted from the largest to the smallest in the Pareto chart presented in Figure 2 that shows the main effect of variables in relation with the slope of the lines. In the Pareto chart all

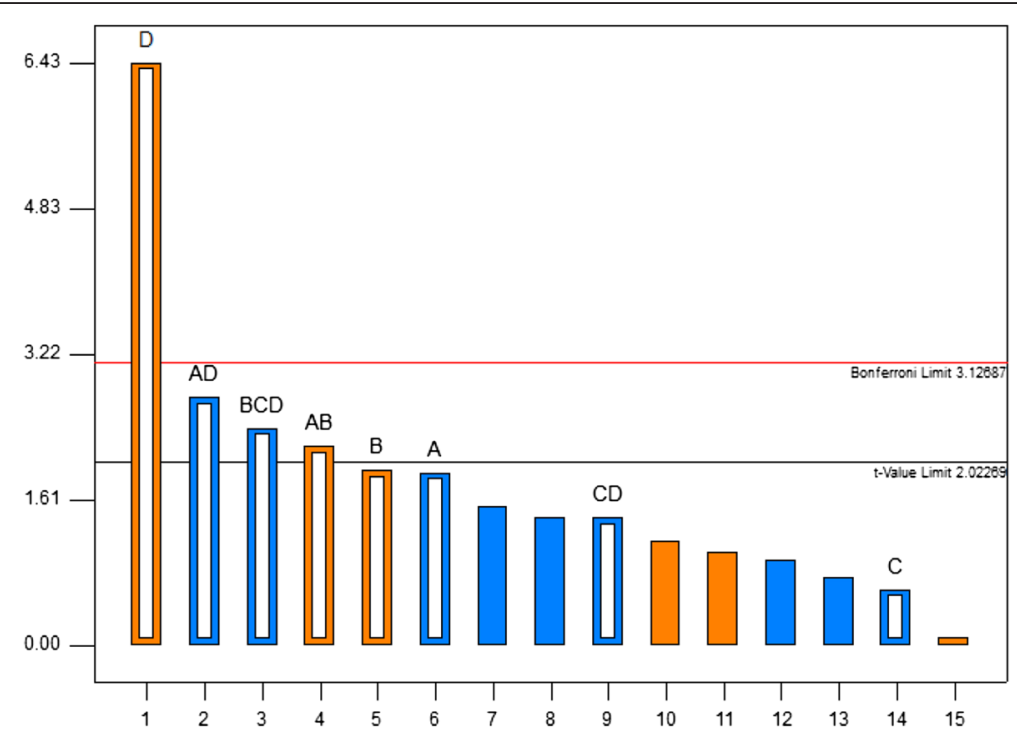

Figure 2 Standardization ( $P=95 \%$ ) main effects Pareto chart for the complete factorial design: A, HA — humic acid (mg/kg); B, Su—Tween $80(\mu \mathrm{L} / \mathrm{L}) ; C$, Sal - salinity (\%W/V); D, Nut- nutrients $(\mathrm{g} / \mathrm{L})$, Red line is Bonferroni limitation line. 
the effect which are in the right the t-value line are significant and each effect which are larger than Bonferroni limitation line have high significant. Hence HA, Su and nutrient were selected as important factors for bioremediation of phenanthrene.

Figure 3 shows the statistical fitness between actual and predicted values. The main effect plot (Figure 3) shows the comparative effects of all parameters on biodegradation of phenanthrene. The slope of nutrient effect shows that the response of phenanthrene removal was sensitive to this factor. The relatively flat line of salinity shows insensitivity of the responses to change in this parameter. The slope of other two parameters confirmed the possibly significant role in the process. Betancur-Galvis et al. [12] reported that the concentration of phenanthrene was 1.7-times and 2.9-times lower in the soil amended with NP and biosolid respectively compared to sterilized soil. In our study application of high level of $\mathrm{N}$ and $\mathrm{P}$ in run 9 had been increased the phenanthrene removal by more than 1.5 fold compared to low level of N and P in run 1. Da Silva et al. [25] showed that bioremediation of coastal sand contaminated crude oil would be improved through biostimulation by using commercial mineral NPK fertilizer.

\section{Optimization and verification}

The structural matrix using three factors CCFD with 4 center points, experimental and predicted responses were presented in Table 2.

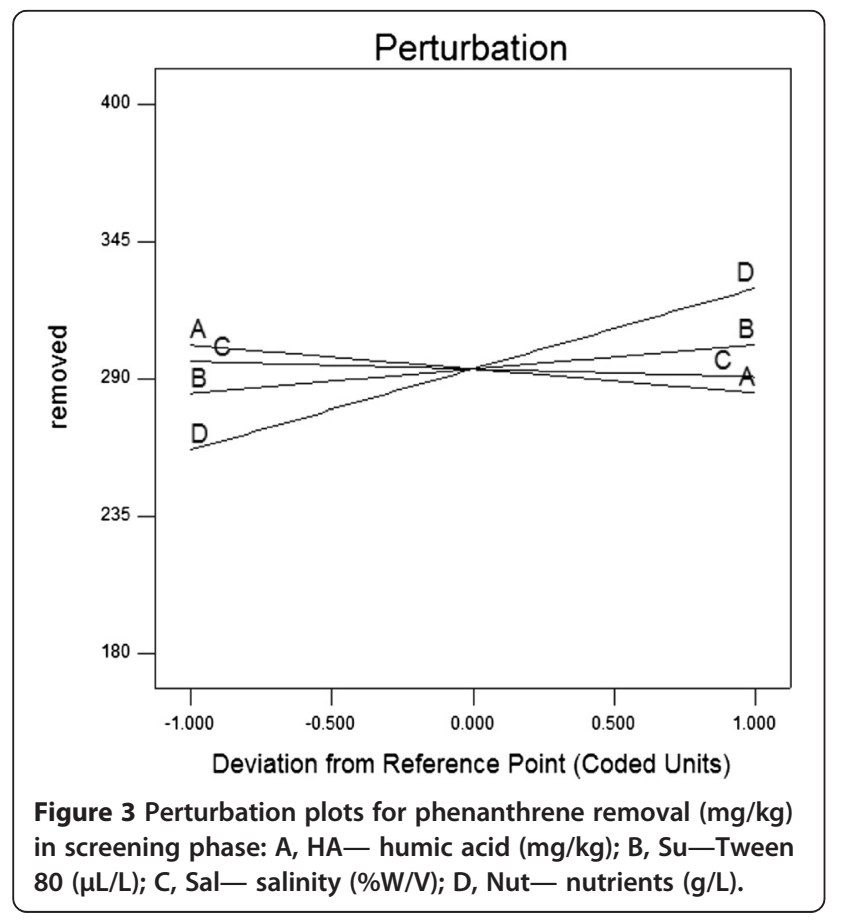

In order to explain the effect of each variable and their interactions on the phenanthrene removal, the firstorder model was given by the following equation (Eq.2):

Removed phenanthrene $(\mathrm{mg} / \mathrm{kg})=297.13+16.08 A+29.28 B+73.82 C$ $+9.38 A B-4.77 A C+8.13 B C$

Where A is HA concentration, B is Surfactant concentration and $\mathrm{C}$ is the concentrations of Nutrient (as $\mathrm{N}$ and $\mathrm{P}$ ). The model was examined by the regression equation and determination coefficient $\left(R^{2}=0.883\right)$ which suggests that more than 88.3 percent of the variance is attributable to the variables (Figure 4). The Fvalue of the regression model was 10.63 , which implied that the application of linear model was satisfactory for the assessment of phenanthrene biodegradation in the soil. Also the low probability value $(<0.0005)$ indicated a high significance of the model. Among the independed variables the linear term of surfactant had significant effect $(\mathrm{P}<0.05)$, while the linear term of nutrient had highly significant effect $(P<0.0001)$ on phenanthrene removal. All the parameters and their interaction had positive effect except the interaction of HA and nutrient had negative effect, which indicated that increasing their levels would decrease the biodegradation of phenanthrene. Figure 5 represent three-dimensional plot of the variables. The parallel contours in Figure $5 \mathrm{a}$, b and c, respectively suggested that interactions of $\mathrm{HA}$ to nutrient, HA to surfactant and surfactant to nutrient could be negligible that confirmed by the percent of their effects which was $<1 \%$.

With emphasis on nutrient effect, lower HA values together with higher nutrient levels or higher HA values together with lower nutrient levels could result in higher biodegradation values. Very slight variations in phenanthrene removal efficiency (Figure $5 \mathrm{a}$ and $\mathrm{b}$ ) were obtained when the HA was used up to concentration of $150 \mathrm{mg} / \mathrm{kg}$ soil corresponding to surfactant and nutrient from low level to high level. The F-ratio of $3.85 \%$ had confirmed it too. In spite of increasing the solubility of $\mathrm{PAH}$ in the presence of humic substance [26,27], HA had no significant effect on phenanthrene biodegradation and it is agree with Heywood et al. [28] who reported that there was not any relationship between PAHs biodegradation and the organic matter content of the soil. The bond between the contaminants and HA can make the contaminants to be more resistant against desorption and biodegradation by microorganisms [29]. Macleod and Semple and Semple et al. reported that in the soil containing humic compounds the mineralization of pyrene occurred with a retardation which was attributed to the slow desorption of HOCs (Hydrophobic Organic Contaminants) as a rate-limiting factor in biodegradation $[15,30]$. In our previous study in presence of humic 

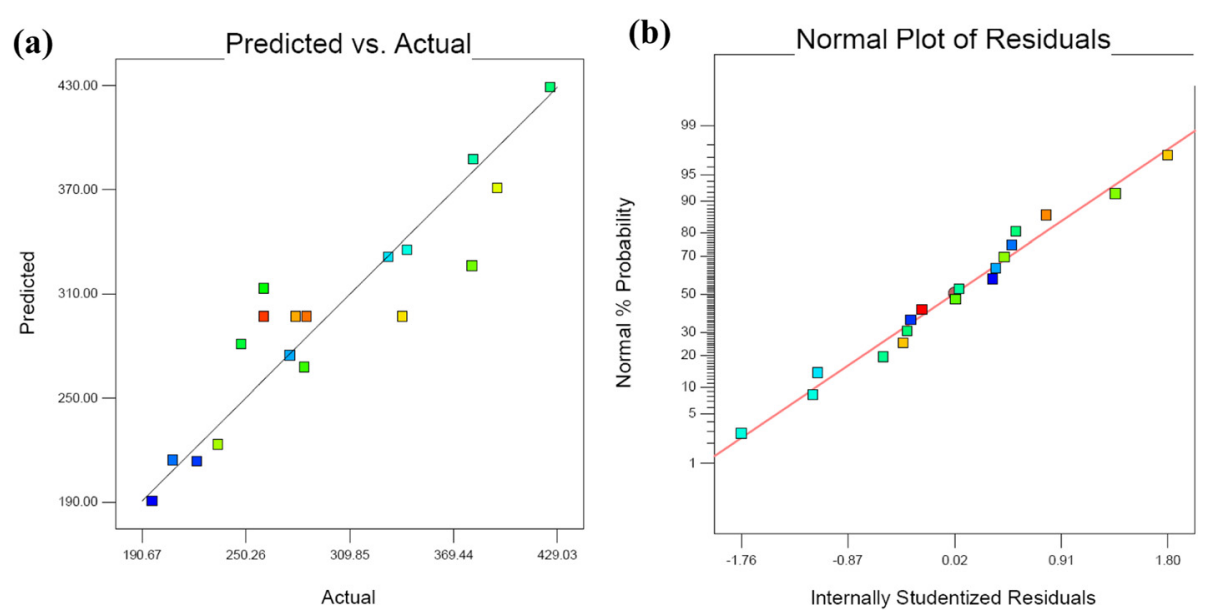

Figure 4 (a) Predicted versus actual and (b) Normal plot of phenanthrene in optimization phase.

compounds, retardation in phenanthrene biodegradation was seen too [6].

The analysis of variance shows that the effect of surfactant on phenanthrene biodegradation was more than HA and less than nutrient. Its middle effect was shown in $3 \mathrm{D}$ plot too (Figure $5 \mathrm{a}$ and $\mathrm{b}$ ). Mixed results have been reported concerning the effect on the biodegradation of PAHs by the addition of surfactant. The positive effect of surfactant is enhancement of biodegradation via increasing in solubility of phenanthrene in water phase which may lead to be more bioavailable for degrading microorganisms $[8,31]$. The negative effect of surfactant has been attributed to be used by microorganisms as a preferential growth substrate or may be toxic for microorganisms because of high amount of contaminant which have been soluble [8]. The lower amount of MPN may be related to high concentration of phenanthrene in liquid phase (data was not shown). The bacterial cell lyses was reported by Avramova et al. [8] in prevention of phenanthrene mineralization by Pseudomonas sp. In their research addition of Triton X-100 inhibited the phenanthrene mineralization too. Piskonen and Itävaara [21] showed that using four types of surfactant at lower concentrations of CMC could not enhance the PHAs bioremediation in contaminated soils.

In Figure 3, a steep slope of in nutrient curve shows that the response of phenanthrene removal was very sensitive to this factor. The effect of this factor was the highest in second phase of experiment too, which was confirmed by ANOVA. Figure $5 \mathrm{a}$ and c. show that nutrient is a crucial factor for the biodegradation of phenanthrene. A highly variation of hydrocarbon biodegradation in the same aquifer samples with nutrient addition was reported in the other research too. Breedveld and Sparrevik [32] observed a strong relation between biodegradation of fluoranthene with nitrogen and phosphorous content. They reported that the transformation rates of hydrocarbons have been increased by addition of inorganic nitrogen and phosphorous. Similar conclusion was also drawn from Coulon et al. [33] who showed that the addition of a commercial oleophilic fertilizer containing $\mathrm{N}$ and $\mathrm{P}$ had a positive effect on degradation of TPH in contaminated sub-Antarctic soil. But it is not agree with Chen et al. [7] who reported that nutrient was the insignificant factor on phenanthrene biodegradation [8].

Enhancement in biodegradation rates of oil-contaminated sediments with addition of inorganic nutrients had been reported before [34]. Nutrient comprises nitrogen, phosphorous and other inorganic elements are essential for bacterial growth [11] and addition of them can enhance bacterial activity, which causes in biodegradation of pollutant [12]. Similar to our research, Mohajeri et al. [35] reported that the higher dose of nutrient amendment can accelerate the phenanthrene biodegradation rate.

The predicted values of phenanthrene removal were calculated from the first-order model and the actual values were determined for particular runs. The predicted versus actual plot of phenanthrene biodegradation and normal percent probability versus the studentized residuals plot were shown in Figure $4 \mathrm{a}$ and $\mathrm{b}$. the similarity between the observed values of experiment and the fitted values under the suggested model indicate that model prediction is accurate. The studentized residuals illustrate the normal distribution, the goodness of fit and linearity of the fitted model.

According to the results, the highest biodegradation $(85 \%=424.8 \mathrm{mg} / \mathrm{kg})$ was obtained from run8 $(150 \mathrm{mg}$ $\mathrm{HA} / \mathrm{Kg}$ soil, $13 \mu \mathrm{g} / \mathrm{L}$ surfactant, and nutrients as $\left.\mathrm{K}_{2} \mathrm{HPO}_{4}: 0.8 ; \mathrm{KH}_{2} \mathrm{PO}_{4}: 0.2 ; \mathrm{KNO}_{3}: 1 \mathrm{~g} / \mathrm{L}\right)$. In this phase the important sequence of the factors was Nutrient, Surfactant and HA with the effect of $81.27 \%, 12.78 \%$ and $3.58 \%$, respectively. 


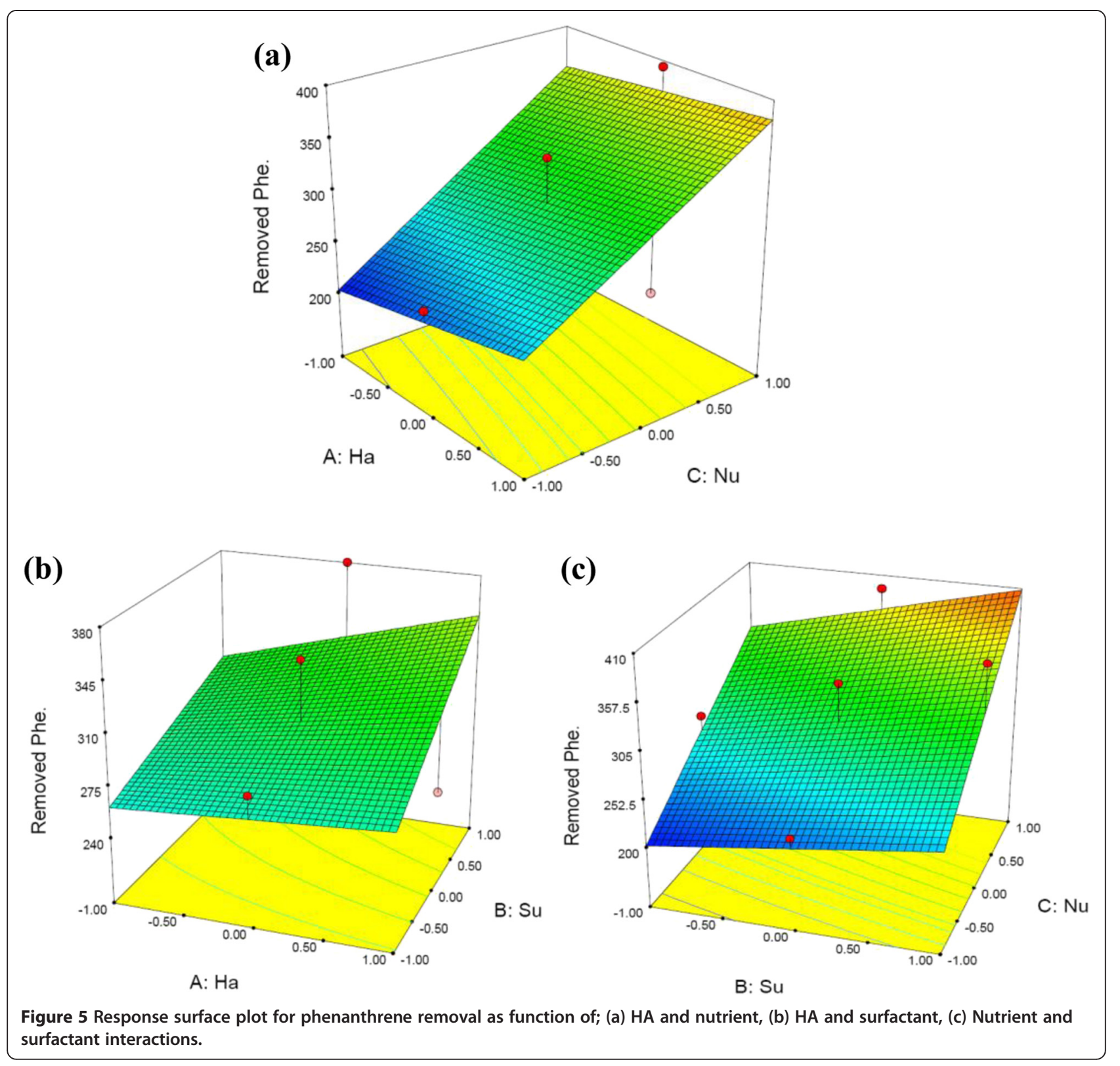

CCFD method predicted that the removal of phenanthrene under the optimum conditions (150 mg HA/Kg soil, $12.68 \mu \mathrm{g} / \mathrm{L}$ surfactant, and nutrients as $\mathrm{K}_{2} \mathrm{HPO}_{4}$ : 0.8 ; $\mathrm{KH}_{2} \mathrm{PO}_{4}: 0.2 ; \mathrm{KNO}_{3}: 1 \mathrm{~g} / \mathrm{L}$ ) will be $87.1 \%$. The average $(n=5)$ of the obtained percent removal of phenanthrene in synthetic contaminated soil under the optimum conditions was $85.3 \pm 1.5 \%$. The potential application of optimum conditions resulted from the model was tested by determining the phenanthrene removal from the real contaminated soil samples. The contaminated soil samples were obtained near the Tehran Petroleum Refinery. The compositions of soil samples were consisted of $69 \%$ sand, $10.0 \%$ silt and $21 \%$ clay and the phenanthrene concentration was in the range of $32-45 \mathrm{mg} / \mathrm{kg}$. The average $(\mathrm{n}=5)$ removal of phenanthrene in contaminated soil samples under the optimum conditions was $72.2 \pm 5.8 \%$. Based on the established results, there are satisfactory agreements between the results for the estimated responses and those obtained under the optimum conditions.

The highest biodegradation rate of phenanthrene in optimum condition was $7.78 \mathrm{mg}$ phenanthrene per $\mathrm{kg}$ soil per day; whereas the phenanthrene biodegradation rate in lowest amount of these factors were only $3.5078 \mathrm{mg}$ phenanthrene per $\mathrm{kg}$ soil per day. Data of this research showed that optimization of effective factors in bioremediation of PAHs contaminated soil could increase the biodegradation rate by two fold of magnitude. 


\section{Conclusions}

The screening experiments showed that significant factors in phenanthrene biodegradation were HA, surfactant and nutrient contents. Therefore, these variables were used for RSM. The obtained results from RSM, point out the importance of nutrients for phenanthrene biodegradation. Surfactant displayed significant positive effect and HA had an insignificant effect on phenanthrene removal. A high similarity was between the model prediction and experimental results. According to the effective ratio, the sequence importance of the variables on phenanthrene biodegradation in contaminated soils were as Nutrient $>$ Surfactant $>$ Humic acid $>$ Salinity. The biodegradation rate at optimum condition was $7.78 \mathrm{mg}$ phenanthrene/kg soil/day.

\section{Competing interests}

The authors declare that they have no competing interests.

\section{Authors' contributions}

MR, RRK, AM, AE, MF and SHN carried out the article with the title of Experimental design approach to the optimization of PAHs bioremediation from artificially contaminated soil: Application of variables screening development participated in the sequence alignment and drafted the manuscript. All authors read and approved the final manuscript.

\section{Acknowledgment}

The authors sincerely thank the Department of Environmental Health Engineering, Tehran University of medical Sciences for financial support of this project.

\section{Author details}

${ }^{1}$ Department of Environmental Health Engineering, School of Public Health, Tehran University of Medical Sciences, Tehran, Iran. ${ }^{2}$ Department of Environmental Health Engineering, School of Public Health, Iran University of Medical Sciences, Tehran, Iran. ${ }^{3}$ Department of Environmental Health Engineering, School of Public Health, Shahid Beheshti University of Medical Sciences, Tehran, Iran. ${ }^{4}$ Department of Chemical Engineering, Biotechnology Group, Tarbiat Modares University, Tehran, Iran.

Received: 4 October 2014 Accepted: 3 March 2015

Published online: 20 March 2015

\section{References}

1. Mahvi AH, Maleki A, Alimohamadi M, Ghasri A. Photo-oxidation of phenol in aqueous solution: toxicity of intermediates. Korean J Chem Eng. 2007;24:79-82.

2. Mohseni Bandpi A, Rezaei Kalantary R, Ameli AEA, Zinatizadeh AA, Jonidi Jafari A. Application of response surface methodology for optimization of Fenton process for phenanthrene removal from soil. Environ Eng Manag J. 2013, in press.

3. Nadim F, Hoag GE, Liu S, Carley RJ, Zack P. Detection and remediation of soil and aquifer systems contaminated with petroleum products: an overview. J Pet Sci Eng. 2000;26:169-78.

4. Nasseri S, Kalantary R, Nourieh N, Naddafi K, Mahvi A, Baradaran N. Influence of bioaugmentation in biodegradation of PAHs-contaminated soil in bioslurry phase reactor. Iranian J Environ Health Sci Eng. 2010;7:199-208.

5. Ressler BP, Kneifel H, Winter J. Bioavailability of polycyclic aromatic hydrocarbons and formation of humic acid-like residues during bacterial PAH degradation. Appl Microbiol Biotechnol. 1999;53:85-91.

6. Rezaei KR, Badkoubi A, Mohseni-Bandpi A, Esrafili A, Jorfi S, Dehghanifard E, et al. Modification of PAHs biodegradation with humic compounds, soil and sediment contamination. An Int J. 2013;22:185-98.

7. Chen J, Wong MH, Wong YS, Tam NFY. Multi-factors on biodegradation kinetics of polycyclic aromatic hydrocarbons (PAHs) by Sphingomonas sp. a bacterial strain isolated from mangrove sediment. Mar Pollut Bull. 2008:57:695-702
8. Avramova T, Sotirova A, Galabova D, Karpenko E. Effect of Triton X-100 and rhamnolipid PS-17 on the mineralization of phenanthrene by Pseudomonas sp. cells. Int Biodeterior Biodegrad. 2008;62:415-20.

9. Borresen $\mathrm{MH}$, Rike AG. Effects of nutrient content, moisture content and salinity on mineralization of hexadecane in an Arctic soil. Cold Reg Sci Technol. 2007:48:129-38.

10. Devi MP, Reddy MV, Juwarkar A, Sarma PN, Mohan SRV. Effect of co-culture and nutrients supplementation on bioremediation of crude petroleum sludge. CLEAN Soil, Air Water. 2011;39:900-7.

11. Liebeg EW, Cutright TJ. The investigation of enhanced bioremediation through the addition of macro and micro nutrients in a PAH contaminated soil. Int Biodeterior Biodegrad. 1999;44:55-64.

12. Betancur-Galvis LA, Alvarez-Bernal D, Ramos-Valdivia AC, Dendooven L. Bioremediation of polycyclic aromatic hydrocarbon-contaminated salinealkaline soils of the former Lake Texcoco. Chemosphere. 2006;62:1749-60.

13. Teng Y, Luo Y, Ping L, Zou D, Li Z, Christie P. Effects of soil amendment with different carbon sources and other factors on the bioremediation of an aged PAH-contaminated soil. Biodegradation. 2010;21:167-78.

14. Minai-Tehrani D, Minoui S, Herfatmanesh A. Effect of salinity on biodegradation of Polycyclic Aromatic Hydrocarbons (PAHs) of heavy crude oil in soil. Bull Environ Contam Toxicol. 2009;82:179-84.

15. Semple KT, Reid BJ, Fermor TR. Impact of composting strategies on the treatment of soils contaminated with organic pollutants. Environ Pollut. 2001;112:269-83.

16. Montgomery DC, Wiley J. Design and Analysis of Engineering Experiments. In: Book Design and Analysis of Engineering Experiments. New York: Wiley; 2001.

17. Khajvand T, Chaichi MJ, Nazari OL, Golchoubian H. Application of BoxBehnken design in the optimization of catalytic behavior of a new mixed chelate of copper (II) complex in chemiluminescence reaction of luminol. J Lumin. 2011;131:838-42.

18. Lu M, Yuan D, Li Q, Ouyang T. Application of response surface methodology to analyze the effects of soil/liquid ratio, $\mathrm{pH}$, and incubation time on the bioaccessibility of PAHs from soil in in vitro method. Water Air Soil Pollut. 2009;200:387-97.

19. Liang Y, Sorensen DL, MCLean JE, Sims RC. Pyrene fate affected by humic acid amendment in soil slurry systems. J Biol Eng. 2008:2:11

20. Maier RM, Pepper IL, Gerba CP. Environmental Microbiology. Canada: Academic Press; 2009.

21. Piskonen R, Itaevaara M. Evaluation of chemical pretreatment of contaminated soil for improved PAH bioremediation. Appl Microbiol Biotechnol. 2004;65:627-34.

22. USEPA. Ultrasonic extraction. Center for environmental research information. EPA, 3550B. 1996;2:1-14

23. Kästner M, Breuer-Jammali M, Mahro B. Impact of inoculation protocols, salinity, and $\mathrm{pH}$ on the degradation of polycyclic aromatic hydrocarbons (PAHs) and survival of PAH-degrading bacteria introduced into soil. Appl Environ Microbiol. 1998:64:359-62.

24. Jacques RJS, Okeke BC, Bento FM, Teixeira AS, Peralba MCR, Camargo FAO. Microbial consortium bioaugmentation of a polycyclic aromatic hydrocarbons contaminated soil. Bioresour Technol. 2008:99:2637-43.

25. da Silva AC, de Oliveira FJS, Bernardes DS, de França FP. Bioremediation of marine sediments impacted by petroleum. Appl Biochem Biotechnol. 2009;153:58-66.

26. Grasso D, Subramaniam K, Pignatello J, Yang Y, Ratte D. Micellar desorption of polynuclear aromatic hydrocarbons from contaminated soil. Colloids Surf A Physicochem Eng Asp. 2001;194:65-74.

27. Van Stempvoort DR, Lesage S, Novakowski KS, Millar K, Brown S, Lawrence $J R$. Humic acid enhanced remediation of an emplaced diesel source in groundwater.: 1. Laboratory-based pilot scale test. J Contam Hydrol. 2002:54:249-76.

28. Heywood E, Wright J, Wienburg CL, Black HIJ, Sara M, Osborn D, et al. Factors influencing the national distribution of polycyclic aromatic hydrocarbons and polychlorinated biphenyls in British soils. Environ Sci Technol. 2006:40:7629-35.

29. Plaza C, Xing B, Fernández JM, Senesi N, Polo A. Binding of polycyclic aromatic hydrocarbons by humic acids formed during composting. Environ Pollut. 2009;157:257-63.

30. Macleod CJA, Semple KT. The adaptation of two similar soils to pyrene catabolism. Environ Pollut. 2002;119:357-64.

31. Ahn CK, Woo SH, Park JM. Enhanced sorption of phenanthrene on activated carbon in surfactant solution. Carbon. 2008;46:1401-10 
32. Breedveld GD, Sparrevik M. Nutrient-limited biodegradation of PAH in various soil strata at a creosote contaminated site. Biodegradation. 2000;11:391-9.

33. Coulon F, Pelletier E, Gourhant L, Delille D. Effects of nutrient and temperature on degradation of petroleum hydrocarbons in contaminated sub-Antarctic soil. Chemosphere. 2005;58:1439-48.

34. Yu KSH, Wong AHY, Yau KWY, Wong YS, Tam NFY. Natural attenuation, biostimulation and bioaugmentation on biodegradation of polycyclic aromatic hydrocarbons (PAHs) in mangrove sediments. Mar Pollut Bull. 2005;51:1071-7.

35. Mohajeri L, Aziz HA, Isa MH, Zahed MA. A statistical experiment design approach for optimizing biodegradation of weathered crude oil in coastal sediments. Bioresour Technol. 2010;101:893-900.

\section{Submit your next manuscript to BioMed Central and take full advantage of:}

- Convenient online submission

- Thorough peer review

- No space constraints or color figure charges

- Immediate publication on acceptance

- Inclusion in PubMed, CAS, Scopus and Google Scholar

- Research which is freely available for redistribution 